\title{
Survey of financial burden of families in the U.S. with children using home mechanical ventilation
}

\author{
Jeffrey D. Edwards MD, MA, MAS ${ }^{1}$ (iD $\mid$ Howard B. Panitch MD \\ Andrei Constantinescu MD, $\mathrm{PhD}^{3}$ | Rachel L. Miller MD ${ }^{4}$ । \\ Patricia W. Stone PhD, $\mathrm{RN}^{5}$
}

${ }^{1}$ Division of Pediatric Critical Care, Department of Pediatrics, Columbia University College of Physician and Surgeons, New York, New York

2 Division of Pulmonary Medicine, Department of Pediatrics, Perelman School of Medicine at the University of Pennsylvania, Philadelphia, Pennsylvania

${ }^{3}$ Division of Pediatric Pulmonology, Department of Pediatrics, Columbia University College of Physician and Surgeons, New York, New York

${ }^{4}$ Division of Pediatric Allergy, Immunology and Rheumatology, Department of Pediatrics, Columbia University College of Physician and Surgeons, New York, New York

${ }^{5}$ School of Nursing, Columbia University, New York, New York

\section{Correspondence}

Jeffrey Edwards, MAS, MD, MA, Division of Pediatric Critical Care, Department of Pediatrics, Columbia University College of Physician and Surgeons, 3959 Broadway, CHN 10-24, New York, NY 10032.

Email: jde2134@columbia.edu

Funding information

National Institutes of Health, Grant number: K23 HD 082361; Columbia University John M. Driscoll, Jr., MD, Children's Fund Award

\begin{abstract}
Aim: To describe and quantify the out-of-pocket expenses, employment loss, and other financial impact related to caring for a child using home mechanical ventilation (HMV). Method: We conducted a cross-sectional survey of U.S. families with children who used HMV. Eligible participants were invited to complete a questionnaire addressing household and child characteristics, out-of-pocket expenses, employment loss/ reduction, and financial stress. Participants were recruited with the help of three national patient registries.

Results: Two hundred twenty-six participants from 32 states (152 with children who used invasive ventilation and 74 with children who used noninvasive ventilation) completed the questionnaire. Participants' median reported yearly household income was $\$ 90000$ (IQR 70000-150000). The median amount paid in out-of-pocket expenses in the previous 3 months to care for their child using HMV totaled \$3899 (IQR $\$ 2900-4550$ ). Reported levels of financial stress decreased as income increased; $37-60 \%$ of participants, depending on income quintile, reported moderate financial stress with "some" of that stress due to their out-of-pocket expenses. A substantial majority reported one or more household members stopped or reduced work and took unpaid weeks off of work to care for their child.

Conclusion: The financial impact of caring for a child using HMV is considerable for some families. Providers need to understand these financial burdens and should inform families of them to help families anticipate and plan for them.
\end{abstract}

\section{KEYWORDS}

artificial, child, cost of illness, family, respiration

\begin{abstract}
Abbreviations: $\mathrm{CSHCN}$, children with special health care needs; $\mathrm{HMV}$, home mechanical ventilation; IQR, interquartile range; NIV, noninvasive ventilation; URL, Uniform Resource Locator.
\end{abstract}

This study was performed at Columbia University Medical Center.

\section{1 | INTRODUCTION}

Home mechanical ventilation (HMV) for children is a resourceintensive, usually long-term medical intervention. Authors of numerous qualitative studies of families with children using HMV have commented on the out-of-pocket expenses and financial burdens associated with the child's domiciliary care. ${ }^{1-4}$ Two studies-one from 
the U.S. 25 years ago $^{5}$ and one recently from Canada ${ }^{6}$-have attempted to quantify these expenses. However, no researchers have studied these expenses and their impact in a recent sample of U.S. families. Moreover, these expenses are not tracked/reported by any agency, and prior research has only focused on inpatient charge estimates normally paid by public or private medical insurance. ${ }^{7}$

Therefore, we conducted a cross-sectional survey of U.S. families with children who use HMV in order to better understand their out-ofpocket expenses and employment loss related to their children's care and the financial stress related to those expenses and losses. These data can be used to provide better anticipatory guidance to families and to inform a full societal perspective cost-of-illness analysis.

\section{2 | MATERIALS AND METHODS}

\section{1 | Participants and recruitment}

Eligible participants were parents or primary caregivers of a child who used HMV and who were residents of the U.S. Their child had to be less than 22 years of age, have used HMV for at least 1 year, and reside in the participant's home. HMV was defined as continuous or intermittent (at least daily) mechanical ventilation via a tracheostomy (invasive ventilation) or noninvasive ventilation (NIV) (ie, continuous positive airway pressure, bilevel positive airway pressure, or mouthpiece ventilation).

Participants were recruited with the help of three patient organizations: International Spinal Muscular Atrophy Patient Registry, Parent Project Muscular Dystrophy, and Cerebral Palsy Research Registry. These organizations queried their registry records to identify families with children under 22 years of age and who self-identified as using $\mathrm{HMV}$ or as having conditions that could be associated with chronic respiratory failure (eg, spinal muscular atrophy type 1 , cerebral palsy with gross motor function classification system level V). The organizations emailed or mailed potential participants a recruitment flyer that explained the purpose of the study and provided a Uniform Resource Locator (URL) for those interested in learning more. This URL took potential participants to a site where study details and the questionnaire could be found. After the study details and before the questionnaire, this site specified that, by completing the questionnaire, the participant affirmed that they read the study details and were providing informed consent to their participation. In addition, the International Spinal Muscular Atrophy Patient Registry posted the study on its website for current research, and Parent Project Muscular Dystrophy posted a notice about the study in its September/October 2016 DuchenneConnect newsletter. Participants who completed the questionnaire also were asked to share the URL with other families they knew who met inclusion criteria. No potential participants were approached or contacted by the investigators themselves. Data were collected anonymously between September and December 2016.

\section{2 | Questionnaire}

A questionnaire was developed based on what has been included in previous studies of direct non-medical and indirect costs of caring for children with chronic conditions $\mathrm{s}^{5,8-12}$ and what is known about caring for children using HMV at home. Closed-ended questions addressed the following areas:

1) The demographic characteristics of the participants and their households, including the household's gross annual income and other caregivers of the child (paid and unpaid).

2) The children's characteristics, including age, underlying condition, modality and frequency of use of HMV, and insurance coverage. We also asked participants about home medical equipment for the child and if it was paid for out-of-pocket.

3) Out-of-pocket expenses for medical supplies, medications, nutrition, professional home care, rehabilitation/complementary services, and other items related to the child's care in the last 3 months.

4) The household's reported degree of financial stress and how much this stress was caused by these out-of-pocket expenses. We also included items assessing self-perceived difficulty paying for necessary expenses (food, housing, utilities) and measures taken to help pay for things related to caring for the child (eg, assistance programs, cutting other expenditures) in the previous year. We asked about assistance programs that the child using HMV or household member(s) participated in during the previous year. Finally, we asked if household members ever had to stop or reduce employment to care for their child and whether this created a financial burden.

Many questions provided space for free text answers to ensure participants could accurately answer and/or comment. A small number of open-ended questions asked about other out-of-pocket expenses, the impact of missed/reduced work, and the financial impact of caring for a child using HMV.

The preliminary questionnaire was revised in a two-stage iterative process. First, using purposeful sampling, four parents of children using HMV followed at Morgan Stanley Children's Hospital of New York participated in cognitive interviews to improve the questionnaire's content validity and readability/comprehension. Second, two additional sets of parents pre-tested the questionnaire for response burden.

The study details, statement of consent, and final questionnaire (available upon request) were rendered into an online survey platform supported by Qualtrics (Qualtrics, LLC; Provo, UT).

All study procedures were approved by the Columbia University Medical Center Institutional Review Board, as well as the Oversight Committee of the International Spinal Muscular Atrophy Patient Registry, which was associated with the Indiana University School of Medicine.

\section{3 | Analysis}

Data were summarized using descriptive statistics (ie, proportions, medians, interquartile ranges [IQR], and ranges), reported in aggregate and stratified by whether the child used invasive ventilation or NIV. Income and expenses were expressed in U.S. dollars. Out-of-pocket 
expenses, as a percentage of the household's reported annual income, were estimated. A mosaic plot of participants' reported financial stress and how much of it was due to their HMV out-of-pocket expenses by income quintiles was constructed to depict how this stress differs by income level. A Spearman's rank coefficient for the correlation between financial stress due to HMV-related out-of-pocket expenses and income quintiles was estimated.

Statistical analyses were performed using Stata 14 (College Station, TX). Statistical significance was determined using a $P$-value of $<0.05$. All qualitative data were transcribed verbatim and imported into NVivo 11 (QSR International Pty Ltd., Australia). Representative examples of the general perspectives expressed by those who answered the open-ended questions were extracted.

\section{3 | RESULTS}

A total of 226 questionnaires were completed. Demographic characteristics of participants and their households are presented in Table 1. Participants' median reported annual household income was $\$ 90000$ (IQR $70000-150000$, range 6800-1 000 000). Households from 32 states were represented. E-table S1 details the paid and unpaid home caregivers. Almost all children received care from professional home caregivers, and more than 50\% received care from one or more unpaid caregivers who were not part of their household. Table 2 details the children using HMV; 152 (67\%) used invasive ventilation and 74 (33\%) used NIV. Children with a range of underlying conditions were represented, though neuromuscular diseases were highly prevalent. Two-thirds of the children were covered by public insurance programs, either fully or through dual coverage. The medical equipment in the home for these children and whether it was paid for out-of-pocket is found in E-table S2. The children represented had a range of home medical equipment, usually respiratory-related; most of this equipment was not paid for out-of-pocket. Other reported equipment paid for out-of-pocket included bath/toilet chair, splints, and end-tidal carbon dioxide monitor.

The median amount paid in out-of-pocket expenses in the previous 3 months to care for their child using HMV totaled $\$ 3899$ (IQR \$2900-4550, range 0-56 800). For families with children using invasive ventilation, it was $\$ 3980$ (IQR 3400-4599). For families with children using NIV, it was $\$ 3515$ (IQR 500-4450). The amounts paid out-of-pocket by participants for particular items or services in the previous 3 months are presented in Table 3; the largest expense was for professional home care. Assuming these expenses were constant over a year, these out-of-pocket expenses represented a median 13.6\% (IQR 7.7-22.6\%) of households' annual income-14.2\% (IQR 8.8-23.4\%) for families of children using invasive ventilation and $11.5 \%$ (IQR 3-19.1\%) for families of children using NIV. Twenty out of 70 participants specifically highlighted the burden of paying out-ofpocket for equipment maintenance/repair; fourteen others highlighted insurance "co-pays" and deductibles for regular and acute medical care. Ten mentioned parking for frequent clinic/hospital visits and items used in the home by non-household caregivers (eg, hand towels, hand sanitizer).

Of the $91 \%(206 / 226)$ of participants that reported moderate or more financial stress, $22 \%$ (15\% with children using invasive ventilation; 35\% with children using NIV) said that "a lot" or "all" of their stress was caused by their out-of-pocket expenses. Twenty percent $(23 \%$ with children using invasive ventilation; $14 \%$ with children using NIV) reported that none of their finance-related stress was caused by their out-of-pocket expenses. Figure 1 shows household finance-related stress and how much of it was caused by these out-of-pocket expenses by income quintiles. Depending on income quintile, $37-60 \%$ of participants reported moderate stress with "some" of that stress due to their out-of-pocket expenses (50-62\% with children using invasive ventilation; $14-56 \%$ with children using NIV [not shown in figure]). There was a negative correlation between financial stress due to HMV-related out-of-pocket expenses and income quintiles (Spearman's ranked correlation coefficient -0.32 $[P<0.0001])$.

Eighty-nine percent of participants reported that household members stopped or reduced working in order to care for their child using HMV (Table 4). They also reported household members commonly took unpaid weeks off of work to care for their child either at home or when hospitalized and that their work sacrifices did cause financial burdens. In open ended questions, 12 out of 70 participants highlighted how household members chose flexibility at work over bonuses or promotions.

E-table S3 shows the assistance programs that the households participated in during the previous year; at least $25 \%$ or participants reported their households received insurance premium assistance and supplement security income. Specific financial hardships experienced or perceived and measures taken to defray the cost of caring for a child using HMV in the previous year are presented in Table 5. At least $50 \%$ of participants reported difficulty paying for food, believed they spend more on transportation because they have a child using HMV, and deferred funding their own life insurance. In addition, $27 \%, 28 \%$, and $60 \%$ reported paying out-of-pocket to move, purchasing a special vehicle, and performing alterations to their home, respectively, because they had a child using HMV.

Representative examples of participants' comments about the impact of missed/reduced work and the financial impact of caring for a child on HMV are found in E-table S4.

\section{4 | DISCUSSION}

This is the first U.S. study to estimate the out-of-pocket expenses and financial burdens of households with children using HMV in this century, and it provides quantitative data to substantiate the assertions of financial burdens experienced by families with children using HMV found in numerous qualitative studies. ${ }^{1-4}$ Using a large cohort from dozens of states, we found that most of these households paid thousands of dollars out-of-pocket to cover expenses associated with caring for their child at home in the previous 3 months and that 
TABLE 1 Survey participants and their households

\begin{tabular}{|c|c|c|c|}
\hline$N, \%$ & Overall $(n=226)$ & $\begin{array}{l}\text { Invasive ventilation } \\
(n=152)\end{array}$ & $\begin{array}{l}\text { Noninvasive ventilation } \\
(n=74)\end{array}$ \\
\hline Household income, yearly, median (IQR) & $\begin{array}{l}\$ 90000 \\
\quad(70000-150000)\end{array}$ & $\begin{array}{l}\$ 95000 \\
\quad(80000-150000)\end{array}$ & $\begin{array}{l}\$ 90000 \\
\quad(50000-130000)\end{array}$ \\
\hline \multicolumn{4}{|l|}{ Employment status } \\
\hline Employed full-time & $174(77)$ & $130(86)$ & $44(59)$ \\
\hline Employed part-time & $9(4)$ & $2(1)$ & $7(9)$ \\
\hline Self-employed & $3(1)$ & $2(1)$ & $1(1)$ \\
\hline Not employed & $28(12)$ & $10(7)$ & $18(24)$ \\
\hline Unreported & $12(5)$ & $8(5)$ & $4(5)$ \\
\hline $\begin{array}{l}\text { Number of adults in household (including participant), median } \\
\text { (IQR) }\end{array}$ & $3(1-5)$ & $3(1-5)$ & $2(1-4)$ \\
\hline $\begin{array}{l}\text { Number of children in household (not including child using HMV), } \\
\text { median (IQR) }\end{array}$ & $1(0-1)$ & $1(0-1)$ & $1(0-1)$ \\
\hline \multicolumn{4}{|l|}{ State of residence ${ }^{a}$} \\
\hline New York & $51(23)$ & $38(25)$ & $13(18)$ \\
\hline California & $32(14)$ & $23(15)$ & $9(12)$ \\
\hline Illinois & $23(10)$ & $19(13)$ & $4(5)$ \\
\hline Florida & $13(6)$ & $8(5)$ & $5(7)$ \\
\hline Colorado & $12(5)$ & $7(5)$ & $5(7)$ \\
\hline Texas & $8(4)$ & $4(3)$ & $4(5)$ \\
\hline New Jersey & $7(3)$ & $4(3)$ & $3(4)$ \\
\hline Ohio & 7 (3) & $5(3)$ & $2(3)$ \\
\hline Arizona & $5(2)$ & $3(2)$ & $2(3)$ \\
\hline Idaho & $5(2)$ & $4(3)$ & $1(1)$ \\
\hline Pennsylvania & $5(2)$ & $2(1)$ & $3(4)$ \\
\hline Virginia & $5(2)$ & $2(1)$ & $3(4)$ \\
\hline Unreported & $11(5)$ & $9(6)$ & $2(3)$ \\
\hline
\end{tabular}

$\mathrm{HMV}$, home mechanical ventilation; IQR, interquartile range.

${ }^{a}$ States with four or less participants: Arizona, Arkansas, Georgia, Idaho, lowa, Kentucky, Louisiana, Maine, Maryland, Massachusetts, Michigan, Minnesota, Missouri, Montana, Nevada, Oklahoma, Oregon, Pennsylvania, South Carolina, Tennessee, Virginia, Washington, West Virginia, Wisconsin, Wyoming.

these expenses were estimated to be greater than $5-10 \%$ of most households' annual income. Most households had one or more members who had to stop or reduce work and take unpaid weeks off of work in order to care for their child using HMV. Many participants reported experiencing specific financial hardships or making financial sacrifices because of these expenses and/or lost/ reduced employment. Finally, we found a weak but significant negative correlation between financial stress due to HMV-related out-ofpocket expenses and income. More than a third of participants reported moderate financial stress with "some" of that stress due to their out-of-pocket expenses, regardless of income quintile. Understanding the financial impact of caring for children using HMV is important for providers who longitudinally follow these children and counsel families before initiating HMV. In addition, measuring costs of care from the family perspective is necessary to inform a full societal perspective cost-of-illness analysis and to inform policy makers and insurers of uncovered expenses.
By providing more recent and more detailed data from a diverse sample of U.S. households, this study expands on previous single-site studies on the financial/employment impact of pediatric HMV on families. In their study of families of children with bronchopulmonary dysplasia requiring invasive long-term ventilation, Miller et al reported that 37 families in Louisiana spent a total of $\$ 30670$ for transportation, meals, child care, lodging during clinic visits and rehospitalizations and household expenses to accommodate equipment needs and \$26 173 for missed work days and employment changes over 4.5 years between 1987 and 1992 (approximately $\$ 341$ per family per year or $\$ 585$ in 2016 dollars, using the U.S. Bureau of Labor Statistics' Consumer Price Index inflation calculator https://www.bls.gov/data/ inflation_calculator.htm). ${ }^{5}$ They also found that one-third of caregivers changed their future financial goals and were unable to work or seek employment due to their infant's illness. More recently, Seear et al had 90 families enrolled in a pediatric home ventilation service in British Columbia, Canada monitor their financial costs of caring for their child 
TABLE 2 Characteristics of children using HMV

\begin{tabular}{|c|c|c|c|}
\hline Characteristic, $n$ (\%) & Overall $(n=226)$ & Invasive ventilation $(n=152)$ & Noninvasive ventilation $(n=74)$ \\
\hline Age, median years (IQR) & $7(6-8)$ & $7(60-8)$ & $7(6-12)$ \\
\hline Age started using HMV, median years (IQR) & $3(2-4)$ & $3(2-3)$ & $3(2-5)$ \\
\hline \multicolumn{4}{|l|}{ HMV usage } \\
\hline$>16 \mathrm{~h} /$ day & $177(78)$ & $138(91)$ & $39(53)$ \\
\hline$<16 \mathrm{~h} /$ day & $49(22)$ & $14(9)$ & $35(47)$ \\
\hline \multicolumn{4}{|l|}{ Underlying condition } \\
\hline Spinal muscular atrophy type 1 & $61(27)$ & $44(29)$ & $17(23)$ \\
\hline Spinal muscular atrophy type 2 & $28(12)$ & $12(8)$ & $16(22)$ \\
\hline Muscular dystrophy & $31(14)$ & $16(11)$ & $15(20)$ \\
\hline Cerebral palsy & $25(11)$ & $19(13)$ & $6(8)$ \\
\hline Hypoventilation (eg, CCHS, obstructive apnea) & $20(9)$ & $15(10)$ & $5(7)$ \\
\hline Chronic pulmonary condition & $14(6)$ & $9(6)$ & $5(7)$ \\
\hline Thoracic cage abnormality & $10(4)$ & $7(5)$ & $3(4)$ \\
\hline Myopathy & $9(4)$ & $6(4)$ & $3(4)$ \\
\hline Diaphragm paralysis & $7(3)$ & $6(4)$ & $1(1)$ \\
\hline Bronchopulmonary dysplasia & $6(3)$ & $5(3)$ & $1(1)$ \\
\hline Other neuromuscular condition & $5(2)$ & $4(3)$ & $1(1)$ \\
\hline Congenital heart disease & $4(2)$ & $4(3)$ & - \\
\hline Spina bifida & $2(1)$ & $2(1)$ & - \\
\hline Spinal cord injury & $2(1)$ & $2(1)$ & - \\
\hline Brain injury/mass & $2(1)$ & $1(1)$ & $1(1)$ \\
\hline \multicolumn{4}{|l|}{ Insurance } \\
\hline Public & $115(51)$ & $74(49)$ & $41(55)$ \\
\hline Private & 77 (34) & $68(45)$ & $9(12)$ \\
\hline Public and private & $34(15)$ & $10(7)$ & $24(32)$ \\
\hline
\end{tabular}

$\mathrm{CCHS}$, congenital central hypoventilation syndrome; HMV, home mechanical ventilation; IQR, interquartile range.

at home over 8 weeks. ${ }^{6}$ These families had considerably lower out-ofpocket expenses than our cohort-a median of $\$ 87.70$ (Canadian dollars) a month (IQR \$15.30-\$472, range \$0-\$3647). Notably, Seear et al also found no correlation between income and the quality of life for children and caregivers. Hefner et al reported an association between financial burden and an unmet need for care coordination, and more than half of their families reported unmet needs for skilled nursing, mostly because of inadequate staffing. ${ }^{3}$

TABLE 3 Amount paid out-of-pocket for items or services for child using HMV in the previous 3 months

\begin{tabular}{llll} 
Item or service, median \$ (IQR) & Overall & Invasive ventilation & Noninvasive ventilation \\
\hline Medical supplies & $400(300-500)$ & $400(300-500)$ & $300(0-500)$ \\
\hline Other supplies & $400(220-540)$ & $450(300-550)$ & $300(60-500)$ \\
\hline Prescription medications ${ }^{\mathrm{a}}$ & $400(220-560)$ & $400(300-535)$ & $350(0-600)$ \\
\hline Nonprescription medications & $300(200-400)$ & $300(200-400)$ & $200(100-400)$ \\
\hline Formula & $150(0-300)$ & $200(50-320)$ & $0(0-300)$ \\
\hline Other nutrition needs & $50(0-200)$ & $100(0-200)$ & $0(0-250)$ \\
\hline Professional home care & $700(400-850)$ & $700(600-875)$ & $600(0-800)$ \\
\hline Rehabilitation services/therapies & $600(417-800)$ & $700(500-800)$ & $500(0-800)$ \\
\hline Complementary/holistic therapies & $600(0-700)$ & $600(400-799)$ & $175(0-600)$ \\
\hline
\end{tabular}

$I Q R$, interquartile range.

ancluded insurance co-pay. 

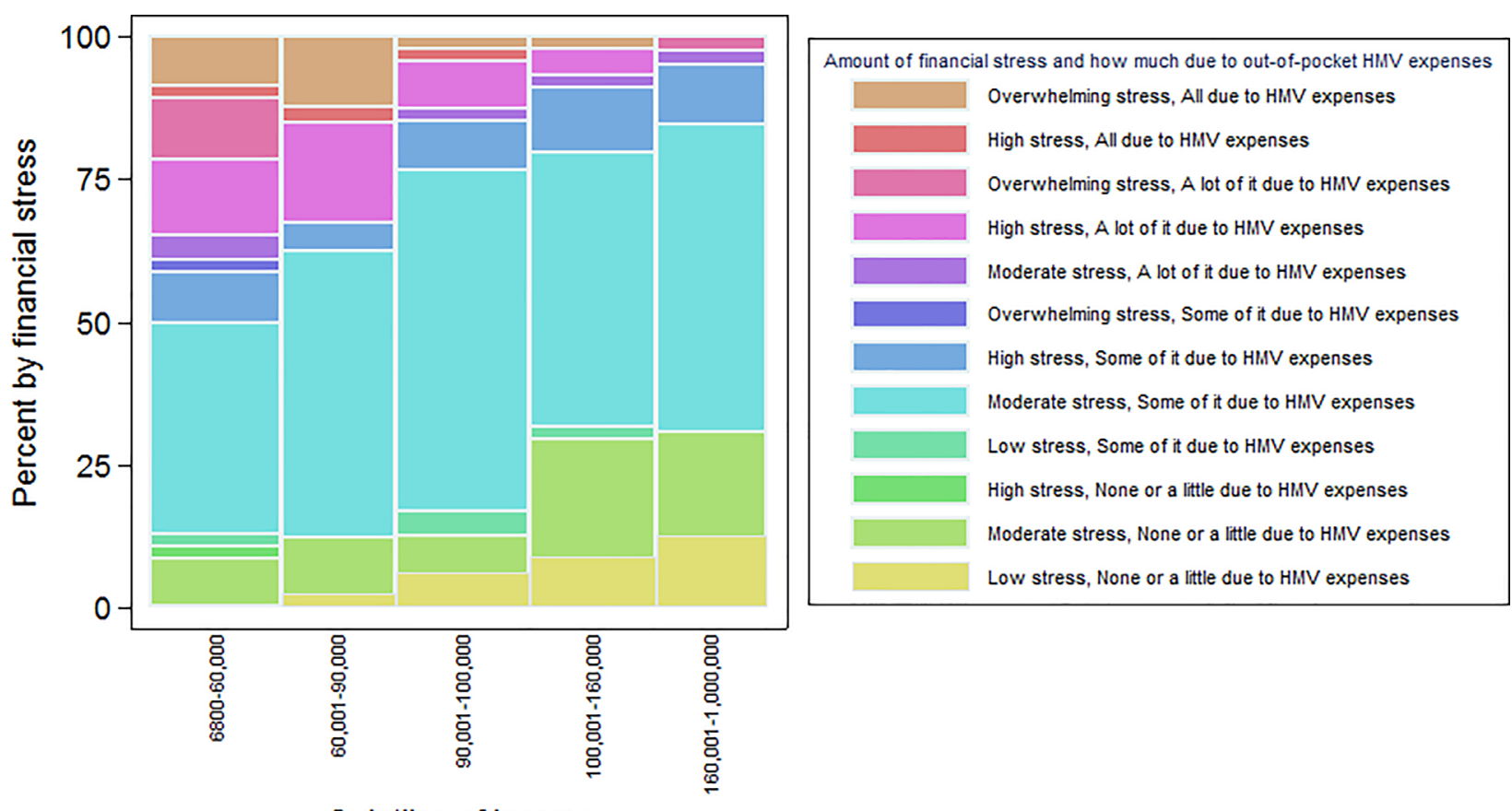

\section{Quintiles of income}

FIGURE 1 Mosaic plot of household finance-related stress and how much of it was caused by HMV-related out-of-pocket expenses by income quintiles

TABLE 4 Impact of caring for child on HMV on household members' employment

\begin{tabular}{|c|c|c|c|}
\hline$N(\%)$ & $\begin{array}{l}\text { Overall } \\
(n=226)\end{array}$ & $\begin{array}{l}\text { Invasive ventilation } \\
(n=152)\end{array}$ & $\begin{array}{l}\text { Noninvasive ventilation } \\
(n=74)\end{array}$ \\
\hline Household member(s) stopped work to care for child & $202(89)$ & $145(95)$ & $57(77)$ \\
\hline Household member(s) decreased work to care for child & $193(85)$ & $134(88)$ & $59(79)$ \\
\hline \multicolumn{4}{|l|}{ Amount of work hours decreased } \\
\hline $10 \%$ & $17(8)$ & $7(5)$ & $10(14)$ \\
\hline $25 \%$ & $78(35)$ & $64(42)$ & $14(19()$ \\
\hline $50 \%$ & $92(41)$ & $64(42)$ & $28(38)$ \\
\hline $75 \%$ & $7(3)$ & $4(3)$ & $3(4)$ \\
\hline $90 \%$ & 7 (3) & $2(1)$ & $5(7)$ \\
\hline Unreported & $25(11)$ & $11(7)$ & 14 (19) \\
\hline Household member(s) not working/working less caused a financial burden & $203(90)$ & $143(94)$ & $60(81)$ \\
\hline $\begin{array}{l}\text { Household member(s) would work/work more if they did not have to care for } \\
\text { child }\end{array}$ & $210(93)$ & $146(96)$ & $64(86)$ \\
\hline $\begin{array}{l}\text { Household member(s) took unpaid leave to care for child at home or in } \\
\text { hospital }\end{array}$ & $188(83)$ & $136(89)$ & $52(70)$ \\
\hline Days of unpaid leave household member(s) took in last year, median (IQR) & $\begin{array}{l}161(59- \\
215)\end{array}$ & $182(112-215)$ & $71(0-196)$ \\
\hline Household member(s) taking unpaid leave caused a financial burden & $183(81)$ & $134(88)$ & $49(66)$ \\
\hline Household member(s) changed job(s) to better care for child & $187(83)$ & $137(90)$ & $50(68)$ \\
\hline $\begin{array}{l}\text { Household member(s) felt their professional opportunities were limited } \\
\text { because of caring for child }\end{array}$ & $206(91)$ & 142 (93) & $64(86)$ \\
\hline
\end{tabular}

HMV, home mechanical ventilation 
TABLE 5 Household financial hardships experienced/perceived and measures taken to defray cost of caring for child using HMV

\begin{tabular}{|c|c|c|c|}
\hline$N(\%)$ & $\begin{array}{l}\text { Overall } \\
(n=226)\end{array}$ & $\begin{array}{l}\text { Invasive ventilation } \\
(n=152)\end{array}$ & $\begin{array}{l}\text { Noninvasive ventilation } \\
(n=74)\end{array}$ \\
\hline \multicolumn{4}{|l|}{ Difficulty paying for in the last year } \\
\hline Food & $114(50)$ & $92(61)$ & $22(30)$ \\
\hline Housing & $99(44)$ & $61(40)$ & $38(51)$ \\
\hline Utilities & $46(20)$ & $21(14)$ & $25(34)$ \\
\hline Utility company shut off or threatened to shut off service & $18(8)$ & $11(7)$ & $7(9)$ \\
\hline \multicolumn{4}{|c|}{ Believed household spent more on because they care for child using HMV } \\
\hline Electricity & $103(46)$ & $60(39)$ & $43(58)$ \\
\hline Transportation & $164(73)$ & $109(71)$ & $55(74)$ \\
\hline Child care for HMV child or sibling & $32(14)$ & $22(14)$ & $10(14)$ \\
\hline Personal/family counseling & $24(11)$ & $10(7)$ & $14(19)$ \\
\hline \multicolumn{4}{|l|}{ Measures taken in the last year } \\
\hline \multicolumn{4}{|l|}{ Decreased or deferred funds for } \\
\hline Utility usage & $39(17)$ & $17(11)$ & $22(30)$ \\
\hline Entertainment & $83(37)$ & $40(26)$ & $43(58)$ \\
\hline Life insurance & $136(60)$ & $104(68)$ & $32(43)$ \\
\hline Retirement & $51(23)$ & $28(18)$ & $23(31)$ \\
\hline College savings & $37(16)$ & $19(13)$ & $18(24)$ \\
\hline Requested a utility waiver or assistance & $12(5)$ & $7(5)$ & $5(7)$ \\
\hline Sold valuable item & $39(17)$ & $26(17)$ & $13(18)$ \\
\hline Took out another mortgage or borrowed against home & $90(40)$ & $75(49)$ & $15(20)$ \\
\hline Borrowed money from family/friends & $74(33)$ & $46(30)$ & $28(38)$ \\
\hline Obtained a cash advance or borrowed against a credit card & $32(14)$ & $12(8)$ & $20(27)$ \\
\hline Took out a personal loan & $14(6)$ & $6(4)$ & $8(11)$ \\
\hline Held a fundraiser & $22(10)$ & $10(7)$ & $12(16)$ \\
\hline
\end{tabular}

HMV, home mechanical ventilation.

As expected, given how care-intensive $\mathrm{HMV}$ is and that most children using HMV are medically complex, the financial impact of HMV on families corresponds and seemingly surpasses the impact reported for families of children with special health care needs (CSHCN). The 2005-2006 National Survey of CSHCN demonstrated that out-of-pocket medical expenses represented $2.2-3.9 \%$ of families' income. ${ }^{13}$ The 2009-2010 National Survey of CSHCN showed that $22 \%$ of families spent over $\$ 1000$ annually on medical out-of-pocket expenses. ${ }^{14}$ Moreover, there is evidence that the financial burdens of families of CSHCN have increased during recent decades, ${ }^{15}$ likely partially due to increased complexity of children who are surviving and living at home. Other studies have found that a quarter to a third of families of $\mathrm{CSHCN}$ have experienced employment loss. ${ }^{16,17}$ Several moderating factors of financial impact have been identified or postulated, including the child's complexity of care needs, family income and employment status, public versus private insurance, and state-level variability in policy and cost-of-living. ${ }^{18-21}$ Other studies have found that families of CSHCN whose providers helped them feel like partners in their child's care and the presence of a medical home were associated with lower odds of reporting financial problems and/or employment loss. ${ }^{13,16,19}$

Given that the impact of HMV extends beyond the child, families of children with chronic respiratory failure should be informed of the financial burden associated with caring for such a child, ideally early and as part of decision-making around initiating HMV. Twelve out of 15 of interviewed directors of pediatric home ventilation programs highlight the financial impact of caring for a child with chronic respiratory failure to families in the course of shared decision-making around initiating $\mathrm{HMV}^{22}$ In addition, commentaries and studies of adult patients and providers have emphasized the importance (and infrequency) of discussing out-of-pocket expenses. ${ }^{23-26}$ Adult patients reported dissatisfaction with the lack of transparency around personal costs of managing their chronic illnesses and that insufficient provider knowledge about such costs and rushed impersonal discussions were impediments to discussing them. ${ }^{27}$

Thus, U.S. families of children with chronic respiratory failure should be told to anticipate HMV-related out-of-pocket expenses and that these expenses can be more than $5-10 \%$ of their income, to anticipate that one or more household members will have to forgo or 
reduce working to help care for the child, that relying on the assistance of unpaid nonprofessionals to help care for the child is common, and that these expenses and work reduction contribute to the financial burdens of many households with children using HMV. Some children with chronic respiratory failure have potentially regressive conditions (eg, bronchopulmonary dysplasia), in which case, the financial impact of HMV may be limited. However, for many families, the impact would likely last for the remainder of the child's life. When financial challenges are a particular concern for a family, providers should delve further into what this might mean for them, which data in studies such as this one can help provide, help families plan financially for the care of the child and their household, and seek alternate funding sources to offset the cost of care when possible.

We should be cognizant that while information on the potential burdens of HMV are imperative to informed decision-making, such information can heighten families' stress and make this decisionmaking all the more difficult (ie, all options seem "bad"). Thus, such information should be presented in a supportive and judicious manner, mindful that the health-related quality-of-life of patients using HMV and their families is variable ("high" for some or in some domains and "low" for others) and relative and that, despite these burdens, many have reported thinking of HMV as a positive thing. ${ }^{26,28-34}$ Information about any potential burden should not be used to dissuade families from choosing HMV.

It is notable that this study occurred after the Affordable Care Act was enacted. Elimination of annual and lifetime dollar limits on health plan benefits and of insurance denials because of pre-existing conditions have likely benefited many of these families and allowed more children with chronic respiratory failure to be cared for at home.

Our study has several strengths and limitations. The questionnaire was comprehensive and adapted from previous validated surveys. The participants represented many geographic areas and a wide range of household income. However, sampling bias may have been introduced as our sample was not random. In addition, it was not possible to estimate a response rate, as we do not know how many people the URL was shared with. Second, people more willing to participate in the survey may be different from the general population of parents with children who use HMV, which would introduce selection bias. Similarly, while impactful, selected responses to open-ended questions may represent a biased perspective, as participants with little financial stress related to the care of their child may not have taken the time to respond. Third, we relied upon participant self-report, so it is not possible to verify responses. However, our large sample size helps to minimize the effect of outlying data. Fourth, the dollar amounts from lost wages were not estimated. Finally, we excluded families with children using $\mathrm{HMV}$ who reside in chronic care facilities, so we cannot comment on their out-of-pocket expenses and financial burdens.

Families of children using HMV commonly experience financial burdens and employment loss/reduction related to or exacerbated by the demands of caring for their child. Providers should be empowered and informed to talk candidly about these and other ramifications of HMV in order to prepare families better before initiating HMV, empathize with the burdens of families, and help mitigate the burdens when possible.

\section{ACKNOWLEDGMENTS}

We sincerely thank all those who participated in this study and those that made it possible, including Connie Garland, Jacqueline Jackson, and Tatiana Foroud, PhD, of the International Spinal Muscular Atrophy Patient Registry; Ann Martin, Holly Peay, and Ann Lucas of Parent Project Muscular Dystrophy; and Theresa Sukal Moulton and Donna Hurley of the Cerebral Palsy Research Registry. We also thank Kira Bona, MD MPH, and Anne-Marie Cirrilla for their insightful suggestions, as well as mentors and advisors, including Suzanne Bakken PhD RN, Joanne Wolfe MD MPH, and Basil Darras MD. Dr Edwards was supported a National Institutes of Health K23 grant (K23 HD 082361) and a Columbia University John M. Driscoll, Jr., MD, Children's Fund Award.

\section{CONFLICTS OF INTEREST}

Dr Panitch discloses funding from the American Board of Pediatrics (medical editor of Pediatric Pulmonology Sub Board, member of sub board), the American Thoracic Society (speaker at postgraduate course, paid honorarium), and Philips Respironics (advisory board for development of mass casualty ventilator), as well as other support from legal reviews for medical malpractice cases. Other authors have no potential conflicts of interest to disclose.

\section{ORCID}

Jeffrey D. Edwards (iD http://orcid.org/0000-0002-8648-248X

\section{REFERENCES}

1. Toly VB, Musil CM, Carl JC. A longitudinal study of families with technology-dependent children. Res Nurs Health. 2012;35:40-54.

2. Carnevale FA, Alexander E, Davis M, Rennick J, Troini R. Daily living with distress and enrichment: the moral experience of families with ventilator-assisted children at home. Pediatrics. 2006;117:e48-e60.

3. Hefner JL, Tsai WC. Ventilator-dependent children and the health services system. Unmet needs and coordination of care. Ann Am Thorac Soc. 2013;10:482-489.

4. Narayanaswami P, Bertorini TE, Pourmand R, Horner LH. Long-term tracheostomy ventilation in neuromuscular diseases: patient acceptance and quality of life. Neurorehabil Neural Repair. 2000;14: 135-139.

5. Miller VL, Rice JC, DeVoe M, Fos PJ. An analysis of program and family costs of case managed care for technology-dependent infants with bronchopulmonary dysplasia. J Pediatr Nurs. 1998;13:244-251.

6. Seear M, Kapur A, Wensley D, Morrison K, Behroozi A. The quality of life of home-ventilated children and their primary caregivers plus the associated social and economic burdens: a prospective study. Arch Dis Child. 2016;101:620-627.

7. Benneyworth BD, Gebremariam A, Clark SJ, Shanley TP, Davis MM. Inpatient health care utilization for children dependent on long-term mechanical ventilation. Pediatrics. 2011;127:e1533-e1541. 
8. Kuhlthau K, Hill KS, Yucel R, Perrin JM. Financial burden for families of children with special health care needs. Matern Child Health J. 2005;9:207-218.

9. Gerber AU, Torre AH, Büscher G, et al. Direct non-medical and indirect costs for families with children with congenital cardiac defects in Germany: a survey from a university centre. Cardiol Young. 2010; 20:178-185

10. Tsimicalis A, Stevens B, Ungar WJ, et al. A mixed method approach to describe the out-of-pocket expenses incurred by families of children with cancer. Pediatr Blood Cancer. 2013;60:438-445.

11. Plumb P, Seiber E, Dowling MM, et al. Out-of-pocket costs for childhood stroke: the impact of chronic illness on parents' pocketbooks. Pediatr Neurol. 2015;52:73-76.

12. Eiser C, Upton P. Costs of caring for a child with cancer: a questionnaire survey. Child Care Health Dev. 2007;33:455-459.

13. Porterfield SL, DeRigne L. Medical home and out-of-pocket medical costs for children with special health care needs. Pediatrics. 2011;128:892-900.

14. U.S. Department of Health and Human Services, Health Resources and Services Administration, Maternal and Child Health Bureau. The National Survey of Children with Special Health Care Needs Chartbook 2009-2010. Rockville, Maryland: U.S. Department of Health and Human Services; 2013:51-52.

15. Ghandour RM, Hirai AH, Blumberg SJ, Strickland BB, Kogan MD. Financial and nonfinancial burden among families of CSHCN: changes between 2001 and 2009-2010. Acad Pediatr. 2014;14:92-100.

16. Okumura MJ, Van Cleave J, Gnanasekaran S, Houtrow A. Understanding factors associated with work loss for families caring for CSHCN. Pediatrics. 2009;124:S392-S398.

17. Thyen U, Kuhlthau K, Perrin JM. Employment, child care, and mental health of mothers caring for children assisted by technology. Pediatrics. 1999;103:1235-1242.

18. Bumbalo J, Ustinich L, Ramcharran D, Schwalberg R. Economic impact on families caring for children with special health care needs in New Hampshire: the effect of socioeconomic and health-related factors. Matern Child Health J. 2005;9:S3-11.

19. Looman WS, O'Conner-Von SK, Ferski GJ, Hildenbrand DA. Financial and employment problems in families of children with special health care needs: implications for research and practice. J Pediatr Health Care. 2009:23:117-125.

20. Parish SL, Shattuck PT, Rose RA. Financial burden of raising CSHCN: association with state policy choices. Pediatrics. 2009;124: S435-S442.

21. Curran AL, Sharples PM, White C, Knapp M. Time costs of caring for children with severe disabilities compared with caring for children without disabilities. Dev Med Child Neurol. 2001;43:529-533.

22. Edwards JD, Morris MC, Nelson JE, Panitch HB, Miller RL. Decisions around long-term ventilation for children: perspectives of directors of pediatric home ventilation programs. Ann Am Thorac Soc. 2017;14: 1539-1547.
23. Alexander GC, Casalino LP, Meltzer DO. Patient-physician communication about out-of-pocket costs. JAMA. 2003;290:953-958.

24. Alexander GC, Casalino LP, Tseng CW, McFadden D, Meltzer DO. Barriers to patient-physician communication about out-of-pocket costs. J Gen Intern Med. 2004;19:856-860.

25. Moriates C, Shah NT, Arora VM. First, do no (financial) harm. JAMA. 2013;310:577-578.

26. Alexander GC, Hall MA, Lantos JD. Rethinking professional ethics in the cost-sharing era. Am J Bioeth. 2006;6:W17-W22.

27. Danis M, Sommers R, Logan J, et al. Exploring public attitudes towards approaches to discussing costs in the clinical encounter. J Gen Intern Med. 2014;29:223-229.

28. Brooks D, King A, Tonack M, Simson H, Gould M, Goldstein R. User perspectives on issues that influence the quality of daily life of ventilator-assisted individuals with neuromuscular disorders. Can Respir J. 2004;11:547-554.

29. Baumgardner DJ, Burtea ED. Quality-of-life in technology-dependent children receiving home care, and their families-a qualitative study. WMJ. 1998;97:51-55.

30. Mah JK, Thannhauser JE, McNeil DA, Dewey D. Being the lifeline: the parent experience of caring for a child with neuromuscular disease on home mechanical ventilation. Neuromuscul Disord. 2008;18:983-988.

31. Lumeng JC, Warschausky SA, Nelson VS, Augenstein K. The quality of life of ventilator-assisted children. Pediatr Rehabil. 2001;4:21-27.

32. Narayanaswami P, Bertorini TE, Pourmand R, Horner LH. Long-term tracheostomy ventilation in neuromuscular diseases: patient acceptance and quality of life. Neurorehabil Neural Repair. 2000;14:135-139.

33. Earle RJ, Rennick JE, Carnevale FA, Davis GM. 'It's okay, it helps me to breathe': the experience of home ventilation from a child's perspective. J Child Health Care. 2006;10:270-282.

34. Mesman GR, Kuo DZ, Carroll JL, Ward WL. The impact of technology dependence on children and their families. J Pediatr Health Care. 2013;27:451-459.

\section{SUPPORTING INFORMATION}

Additional Supporting Information may be found online in the supporting information tab for this article.

How to cite this article: Edwards JD, Panitch HB, Constantinescu A, Miller RL, Stone PW. Survey of financial burden of families in the U.S. with children using home mechanical ventilation. Pediatric Pulmonology. 2018;53:108-116. https://doi.org/10.1002/ppul.23917 